\title{
Método de diagnóstico y valoración de daños en acabados por flecha diferida de forjados de hormigón
}

\section{Method of damage diagnosis and valuation in finishing by long-term deflection of filled slabfloors}

\author{
Javier Pinilla $^{(*)}$, Felix Lasheras ${ }^{(*)}$
}

\section{RESUMEN}

Los daños generados por la flecha diferida de los forjados de hormigón generan múltiples reclamaciones judiciales. Esta investigación se centra en la cuantificación y valoración técnica de los daños, principalmente fisuras en tabiques y techos, y presenta un método para auscultarlas y evaluar objetivamente los grados de afectación de estos daños en aras a la valoración económica de la reparación. Se muestran diferentes herramientas novedosas para medir la amplitud de las fisuras y fichas sencillas que facilitan la toma de datos de la localización, dimensiones y tipos de fisuras. También se desarrolla un método para evaluar la evolución de los movimientos de estructuras mediante testigos de clavos y para su colocación. Finalmente se presentan seis casos de estudio que muestran el proceso de inspección y de valoración técnica, y que también muestran la influencia de los diferentes tipos estructurales en los daños generados.

Palabras clave: fisuras; flecha diferida; grado de afectación; fluencia.

\section{ABSTRACT}

Damages generated by the long-term deflection of the filler slab floors produce multiple legal claims; the phenomenon has been widely studied and is known, so the cause and origin of damage are not in discussion. This research focuses on the quantification and technical valuation of damages, mainly cracks in partitions and ceilings, a method for auscultation of cracks and objectively evaluating the degree of affectation of these damages in the field of residential building is described, with the objective of estimate the cost of the repair. This paper shows different novel tools to measure the amplitude of cracks and sheets that make easier the data collection on location, dimensions, and types of cracks. A method to evaluate the evolution of structural movements using calibrated control nails is described. Finally, six case studies are analyzed to verify the influence of the different structural types on damage generated.

Keywords: cracks: long-term deflection; degree of affectation; creep.

(*) Universidad Politécnica de Madrid, (España).

Persona de contacto/Corresponding author: javier.pinilla@upm.es (J. Pinilla)

ORCID: http://orcid.org/oooo-0oo2-9390-2083 (J. Pinilla); https://orcid.org/oooo-0002-1252-5360 (F. Lasheras)

Cómo citar este artículo/Citation: Javier Pinilla, Felix Lasheras (2022). Método de diagnóstico y valoración de daños en acabados por flecha diferida de forjados de hormigón. Informes de la Construcción, 74(565): e426. https://doi.org/10.3989/ic.81773

Copyright: (C) 2022 CSIC. Este es un artículo de acceso abierto distribuido bajo los términos de la licencia de uso y distribución Creative Commons Reconocimiento 4.0 Internacional (CC BY 4.0). 


\section{INTRODUCCIÓN}

Las fisuras producidas en elementos de tabiquería generadas por la deformación de las estructuras ocupan el cuarto puesto en el listado de daños con más casos en reclamaciones judiciales en el periodo comprendido entre el año 2008 y 2013 en España (1). De acuerdo con J. Calavera et al. (2), el problema empezó en los años 1970 y tiene sus principales causas en:

- Aumento de luces de proyecto. En los años 1960 las luces estructurales en edificios de viviendas estaban en torno a $4^{\prime} 5 / 5 \mathrm{~m}$. Actualmente están en $6-7 \mathrm{~m}$, lo que incrementa las flechas respecto a la situación anterior hasta un $73 \%$.

- Empleo de aceros de alta resistencia. La aparición de aceros B40os en los años 1960/70 supuso una reducción del momento de inercia de la sección de hormigón armado que implica un aumento de las flechas en torno a un $69 \%$. Reducción de coeficientes de seguridad. La introducción de la teoría de los estados límites en las normas, a partir de los años 1970, conllevó una reducción de los coeficientes de seguridad con la consecuente reducción del momento de inercia y aumento de flecha

Otras causas residen en el empleo de vigas planas sin descuelgue. El encarecimiento de la mano de obra propició la proliferación de forjados con vigas planas para no encofrar vigas descolgadas, lo que lleva a forjados sobredimensionados, con el consiguiente aumento de peso propio y reducción del canto de las vigas.

La aparición de fisuras por la flecha diferida de la estructura genera multitud de demandas a los agentes de la construcción en el caso de vivienda colectiva con reclamaciones que a veces tienen un alto importe económico. En España no existe un criterio límite para la valoración técnica objetiva del grado de afectación que estas fisuras, principalmente caracterizadas por su amplitud, longitud y número, suponen para los elementos afectados, es decir tabiques y techos. Además, en muchos casos, el elevado número de este tipo de fisuras hace engorrosa su medición y cuantificación, de tal manera que no es fácil valorar pormenorizadamente la reparación de los daños ocasionados, lo que genera disparidad de criterios en las valoraciones periciales de las distintas partes implicadas en los procedimientos judiciales. El presente artículo muestra un método objetivo para evaluar el grado de afectación de cada vivienda en función de número de fisuras y de la longitud y amplitud de cada una de ellas, para evaluar más ajustadamente el coste de reparación de los daños.

La deformación total que se produce en un elemento de hormigón por flexión es la suma de varias deformaciones parciales principalmente debidas al efecto de las cargas, de la fluencia y retracción del hormigón, y a la relajación de las armaduras. Al entrar en carga la estructura se produce una primera deformación en un corto periodo de tiempo, que se denomina instantánea. Durante los primeros años de servicio de la estructura le sigue otra deformación, que se denomina diferida, principalmente debida a la fluencia del hormigón. La progresión de esta deformación es paulatinamente decreciente con el tiempo: crece más en los primeros años y se suele dar por terminada antes de los 10 años, casi siempre. Ambas deformaciones, instantánea y diferida, son de parecido orden de magnitud, por lo que tienen similar importancia y deben considerarse de igual manera.

La mayor parte de las fisuras por flecha diferida aparecen en los primeros años de vida de la estructura, normalmente entre el primero y el segundo año, que es cuando se producen las mayores deformaciones, aunque tardan algún tiempo más en estabilizarse porque la estructura sigue deformando durante unos años a la vez que se descarga sobre la tabiquería, si bien lo hace de forma progresivamente decreciente: la deformación de cada año es significativamente menor que la anterior, hasta que prácticamente se detiene y los tabiques van rompiendo según llega a su límite de deformación o de resistencia. Simplificadamente, y para el cálculo durante la fase de proyecto, se considera que la flecha diferida se estabiliza a los 5 años; así, se estima que a las dos semanas de la puesta en carga de la estructura se ha producido el $25 \%$ de dicha flecha, al mes el $35 \%$, a los tres meses el 50\%, a los seis meses el 60\%, al año el 70\%, y a los 5 años el 100\% (3). La deformación de forjados y vigas va comprimiendo a los tabiques inferiores hasta que éstos llegan al citado límite de deformación o de resistencia, de forma que el momento de rotura va retardado respecto al de mayor crecimiento de la deformación de la estructura. A su vez, la rotura de los tabiques conlleva su descarga y la redistribución de cargas y deformaciones sobre otros tabiques, lo que alarga el proceso de aparición y estabilización de los daños un tiempo indeterminado que la experiencia muestra que sólo excepcionalmente se alarga más de los 10 años mencionados.

Los tabiques cerámicos, por su constitución, tienen una elevada rigidez y fragilidad, por lo que admiten limitadas deformaciones antes de romperse. Por el contrario, la estructura y los forjados que soportan a los tabiques tienen una flexibilidad y deformabilidad mucho mayor que, en muchos casos, llega a ser incompatible con la de la tabiquería cerámica. Las fisuras aparecen cuando las deformaciones y tensiones forzadas en los tabiques por la deformación de la estructura son mayores que las que pueden soportar.

El fenómeno es ampliamente conocido, por lo que las normas que afectan al diseño y cálculo de estructuras limitan las deformaciones esperables según las condiciones de cálculo. La norma EHE-o8 (3), limita la flecha total a L/250, siendo $L$ la luz de la viga, y la flecha activa a $L / 400$ o a $1 \mathrm{~cm}$, y da procedimientos aproximados de cálculo para prevenirlas en fase de proyecto, basados en la fórmula de Branson (2), así como algunas advertencias al respecto.

En condiciones normales, en las fisuras debidas a flecha diferida no es necesario intervenir en la estructura, puesto que una vez que su deformación se estabiliza no se repiten los daños por la propia naturaleza del fenómeno. Así pues, una vez estabilizadas las fisuras solo queda reparar los daños, cuyo coste va en función del grado de afectación de éstos a las viviendas.

En algunas guías de peritos (4) se recogen las herramientas más utilizadas para la medición de la amplitud de las fisuras, que son las tarjetas de fisuras, y para controlar su movimiento los testigos de yeso, tornillos y fisurómetros, pero no suelen darse recomendaciones precisas sobre la 
instalación de los testigos que, bien colocados, pueden dar la mejor información posible. Por otro lado, cada técnico suele usar su propio sistema para representar en planos las condiciones de las fisuras, aunque existe algún trabajo pionero en este campo (5); no obstante, estos sistemas adolecen de cierta complejidad que los hacen poco operativos en el día a día de la inspección, siendo más fácil multiplicar las tomas fotográficas. También, y por ejemplo, existen protocolos para documentar las grietas y fisuras en situaciones específicas, como en edificios colindantes antes la ejecución de una obra nueva con sótanos (6). Finalmente, existen múltiples estudios sobre el lenguaje de las fisuras y las grietas para establecer la relación entre sus condiciones formales y las causas que provocaron su aparición (7).

\section{METODOLOGÍA}

Durante varios años hemos ido desarrollando un procedimiento para la inspección y valoración de fisuras que, finalmente, hemos contrastado en un total de 291 viviendas en las que medimos un total de 2.021 fisuras. Las inspecciones se han realizado más de siete años después de la puesta en carga de la estructura. El control de fisuras mediante testigos de movimiento lo realizamos en cuatro viviendas con una antigüedad superior a 13 años, con un testigo en cada vivienda. Los datos obtenidos se recogen en dictámenes que en algunos casos han sido utilizados en procedimientos judiciales.

\subsection{Auscultación}

La inspección de las viviendas se hace por uno o más equipos de al menos dos personas, dependiendo del número de viviendas a inspeccionar y del tiempo disponible. Una persona se encarga de fotografiar y medir las fisuras, y la otra recoge los datos que se indican en fichas como la de la figura 2. Las fisuras se representan en croquis de forma rápida y sencilla dejando los detalles para su mejor representación en las fotografías, que siempre se hacen de forma que sea reconocible el punto de toma, el entorno de la fisura y con luz natural (sin flash) salvo que no sea posible. Una vez numeradas las fisuras de la vivienda, los principales datos que se toman son:

- Localización. En un plano se sitúan tanto las fisuras observadas como los posibles testigos que se coloquen, con indicación de su numeración y los puntos de toma fotográficos si fuera conveniente.

- Tipo. Para facilitar el análisis posterior, durante la inspección se realiza una primera clasificación en función de los siguientes tipos de fisuras, con su letra de codificación:

- a: Atravesada (techo). Fisuras en falsos techos de escayola a $45^{\circ}$ con respecto a las paredes de la estancia.

- $d$ : Desprendimiento. Despegues de guarnecidos de yeso respecto del tabique, debidos a compresiones.

- e: Esquina $(v)$. Fisuras verticales en esquinas, normalmente de mochetas.

- $h$ : Horizontal. Fisuras horizontales en tabiques.

- $i$ : Inclinada. Fisuras inclinadas, normalmente a $45^{\circ}$, en tabiques. Si el ángulo es diferente, se anota en la ficha.

- j: Junta (falso techo). Fisura en junta de placas de escayola o de yeso laminado de falsos techos.

- $r$ : Rincón (tabique-techo). Fisura o aplastamiento en rincón entre techo y tabique.
- $t$ : Techo (trasdosado de fachada-techo). Fisura o aplastamiento en rincón entre techo y trasdosado de fachada.

- $\quad v$ : Vertical. Fisura vertical en tabique o trasdosado.

- z: Zigzag (4/И, N, S, Z). Grupo de fisuras inclinadas paralelas a lo largo de una línea, típicas de deformaciones o esfuerzos cortantes. Si añadimos "mentalmente" unas flechas imaginarias a este tipo de fisuras, podemos designarlas como "4" о " $И$ " ("N" simétrica) si la inclinación de las fisuras es de $45^{\circ}$ (figura 1.a), o como "N" si es de $-45^{\circ}$ (o $315^{\circ}$ ) (figura 1.b). Las alineaciones horizontales se designan como "Z" si son a $45^{\circ}$ (figura 1.d) o como "S" si son a $-45^{\circ}$ (figura 1.c). Las flechas nos señalan la dirección y el sentido de los desplazamientos relativos.

- Avance. Se indica mediante una flecha con dirección (vertical, horizontal o inclinada) y sentido (de mayor a menor abertura). Indica hacia donde avanza longitudinalmente la fisura.

- Longitud " $L$ " (m). Medida en metros, normalmente medida con flexímetro o aproximada a partir de las dimensiones del tabique.

- Amplitud "a" (mm). Anchura máxima de la fisura en milímetros, medida con las siguientes herramientas en función del rango ${ }^{1}$ :

- $a<0$ '5mm. Galga de espesores (figura 3.a).

- o'45<a<3'omm. Galga para toberas (figura 3.b).

- $a<5 \mathrm{~mm}$. Calibre cónico con una precisión de o’o1mm (figura 3.c).

- o'1mm<a. Lupa micrométrica (figura 8.b).

- o'o5<a<2'oomm. Regla de fisuras.

- Observaciones. Se anota cualquier circunstancia relevante, como si hay un resalte o tecleo a ambos lados de la fisura, y su magnitud (medida con galga o calibre), coincidencia con rozas o con fisuras en la otra cara del tabique, continuidad en paramentos ortogonales, etc.

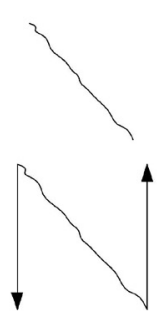

(a)

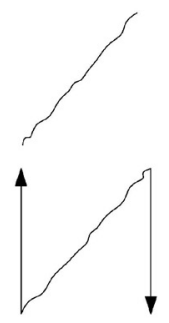

(b) (c)

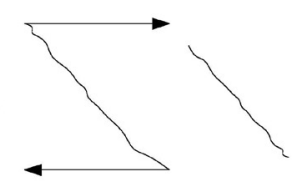

(d)

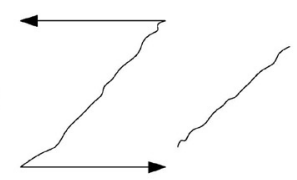

Figura 1. Tipos de fisuras en zigzag: Grupos verticales (a) en “4”, (b) en "N" y horizontales (c) en "S" y (d) en " $Z$ ". 


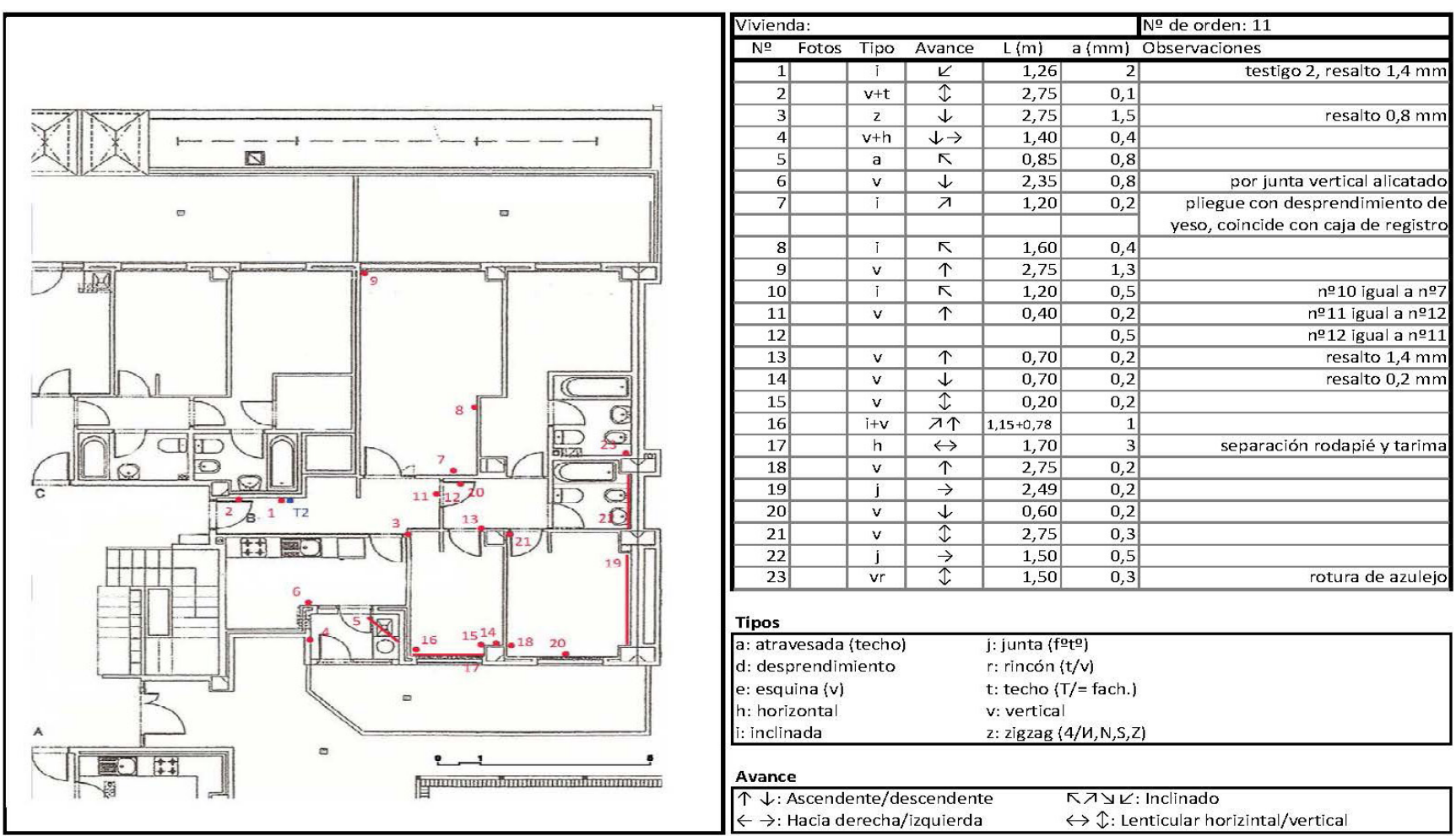

Figura 2. Ejemplo de ficha de toma de datos de fisuras en vivienda. En la planta se marca en rojo la posición de las fisuras numeradas y en azul se marca la posición de los testigos numerados. En la tabla se apuntan las características de las fisuras.

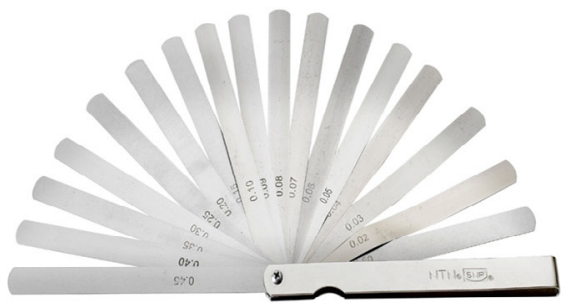

(a)

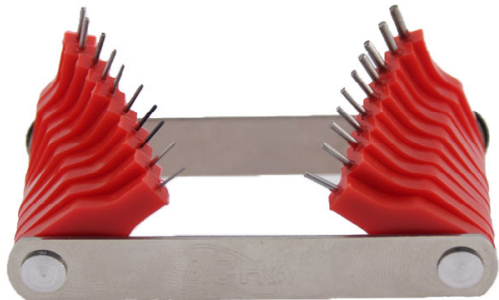

(b)

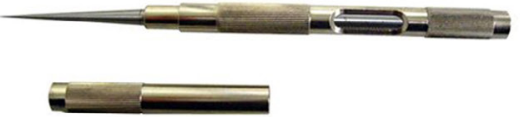

(c)

Figura 3. Herramientas para la medición de amplitud de fisuras: (a) Galga de espesores o'o5-1'omm, (b) galga para toberas o’45-1'5mm y 1'5-3’omm y (c) calibre cónico o’o1-5'oomm.

\subsection{Seguimiento de movimientos}

Para comprobar la estabilización de la estructura, si se tienen dudas al respecto, hay que medir la evolución de las fisuras durante un cierto tiempo nunca menor a seis meses, aunque lo ideal es que sea de un año, al menos. En este tiempo hay que medir la evolución de la humedad y de las temperaturas para discriminar las deformaciones estructurales de las higrotérmicas. Para control continuo de fisuras existen técnicas muy conocidas como las regletas de retícula, extensómetros capacitivos o los fisurómetros digitales.

Un método sencillo, suficientemente preciso y con poco impacto para poder medir los movimientos de la estructura, son los clavos para control con calibre Vernier, consistente en la medición de la abertura de la fisura mediante la colocación de clavos a los lados de la fisura y mediciones de distancias con calibre o pie de rey digital con precisión de o’o1mm (8). El empleo de 3 o 4 clavos adecuadamente colocados permite obtener directamente datos como la abertura de la fisura a la vez que el asiento (vertical) y el desplazamiento (horizontal) que pudieran tener las dos partes de los tabiques separadas por la fisura. Además, las lecturas de los lados que no atraviesan a la fisura, teóricamente constantes a lo largo de todo el tiempo de monitorización, sirven para calibrar la exactitud y la precisión del método de lectura y del instrumental utilizado en ésta. Usamos las siguientes disposiciones para la monitorización de fisuras (los clavos o vértices del polígono se designan siempre empezando por el primero más alto y a la izquierda y en el sentido del reloj):

- Triangulo rectángulo (figura 4). Se utiliza para fisuras inclinadas. La hipotenusa se traza perpendicular a la fisura. En función de la posición de los puntos respecto a la fisura obtenemos los siguientes valores:

- Cateto vertical cruza la fisura (figura 4.a). Los incrementos de medición del cateto vertical, $b$, indican el asiento, los incrementos de la hipotenusa, $a$, la abertura de la fisura y el cateto horizontal, $c$, nos da información sobre la exactitud de la medición. 
- Cateto horizontal cruza la fisura (figura 4.b). Los incrementos de medición del cateto horizontal, $c$, indican el desplazamiento, los incrementos de la hipotenusa, $a$, la abertura de la fisura y el cateto vertical, $b$, nos da información sobre la exactitud de la medición.
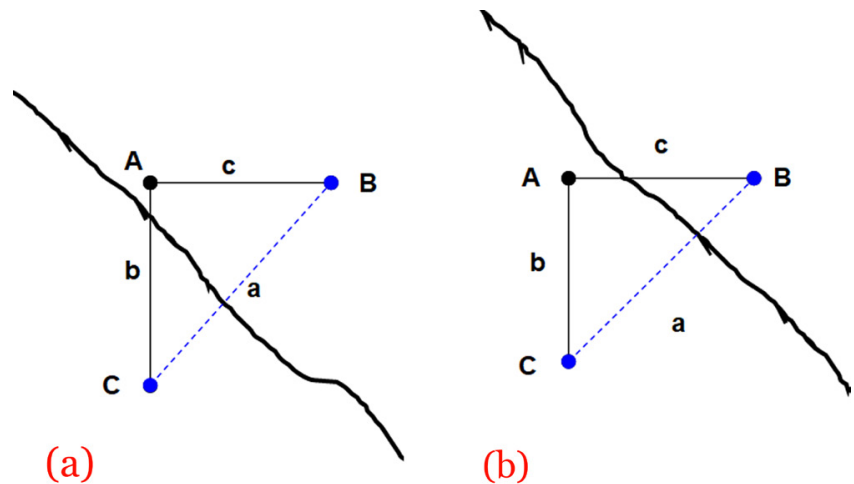

(a)

(b)

Figura 4. Triangulo rectángulo en fisura inclinada.

- Triangulo isósceles (figura 5.a). Sirve para cualquier posición de fisura, pero es el que menos información da. Se traza con la base paralela a la fisura. La medición de la base, $c$, da información sobre la exactitud de la medición, la abertura de la fisura se obtiene de la fórmula de la altura de un triángulo isósceles:

$$
h=\sqrt{a^{2}-\frac{b^{2}}{4}}
$$

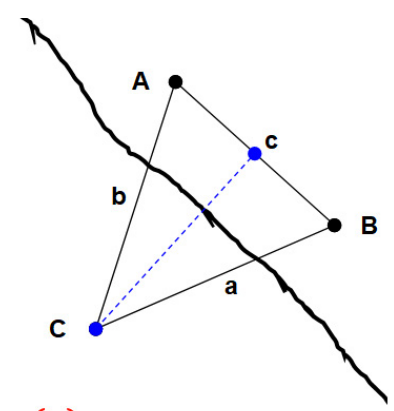

(a)

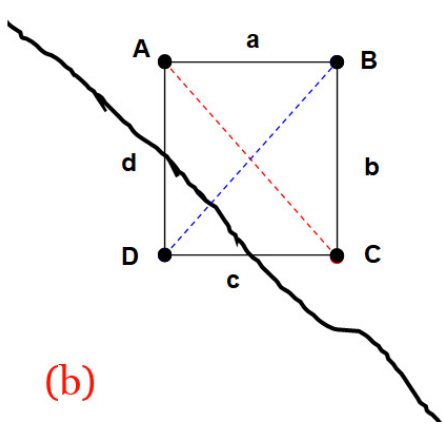

Figura 5. Disposiciones en fisuras inclinadas: (a) triangulo isósceles, (b) rectángulo.

- Rectángulo. Es la disposición que más información nos da y también sirve para cualquier dirección, siendo idónea para las fisuras horizontales o verticales (donde puede ser un cuadrado), e inclinadas (donde puede ser un rombo):

- Fisuras inclinadas (figura 5-b y 7). La diagonal DB se traza perpendicular a la fisura. Los incrementos de medición del lado vertical que cruza la fisura, $d$, indican el asiento. Los incrementos de medición del lado horizontal que cruza la fisura indican el desplazamiento. Las diferencias de medición de la diagonal que cruza la fisura, $B D$, indican la variación de abertura de la fisura. Finalmente, los otros lados sirven para conocer la exactitud de la medición y evitar que un error de anotación o de lectura invalide toda la medición.

- Fisura horizontal (figura 6.a). Los incrementos de medición de los lados verticales indican el asiento, las mediciones de lados horizontales sirven para conocer la exactitud de la medición.

- Fisura vertical (figura 6.b). Los incrementos de medición de los lados horizontales indican el desplazamiento, las mediciones de lados verticales sirven para conocer la exactitud de la medición.

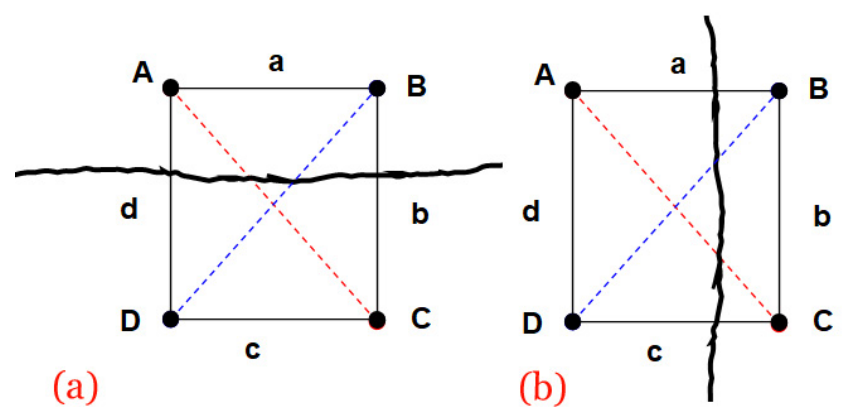

Figura 6. Disposiciones en rectángulo: (a) fisuras horizontales, (b) fisuras verticales.

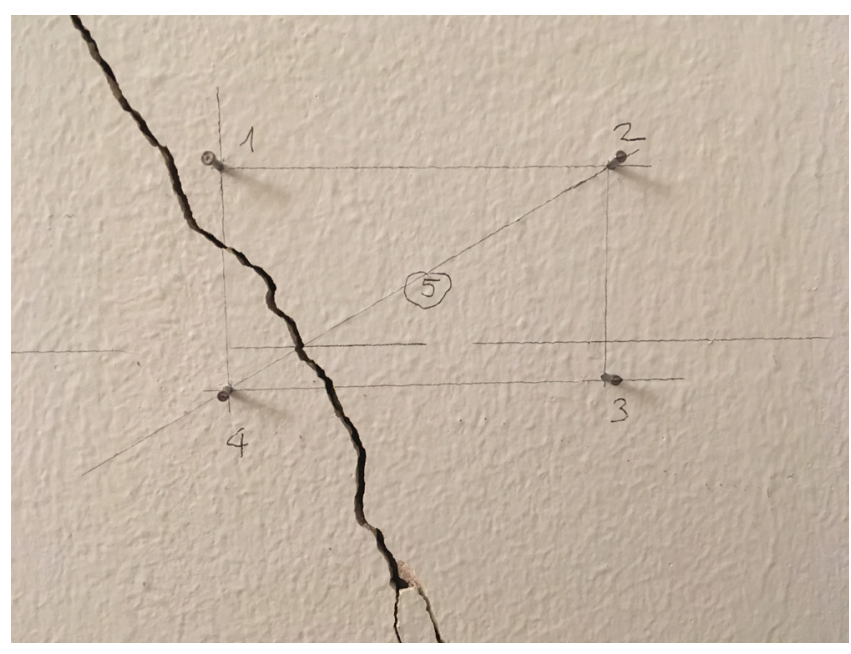

Figura 7. Medición de distancias entre puntos de control.

La lectura de las distancias entre los vértices del cuadrilátero testigo se ha realizado con un calibre digital Vogel Digi Plus-Line, modelo 202010, con certificado de calibración CO86392 y precisión de o’o1mm.

Cada distancia se mide tres veces en cada día de lectura, comprobando el cero de lectura antes de efectuar cada una de ellas. Todos los datos se ordenan en tablas de una hoja de cálculo para obtener los valores medios de cada longitud medida. Con estos valores se calculan los errores estadísticos de lectura bajo la hipótesis de que siguen una distribución nor- 
mal. Para cada lado o diagonal del cuadrilátero de cada testigo se adopta como medida cierta del día la media de sus tres lecturas, salvo que alguna sea estadísticamente anormal, en cuyo caso se rechaza, utilizándose entonces las dos restantes.

\subsection{Clasificación de fisuras por elemento afectado}

Se distinguen tres grupos de fisuras según elementos afectados:

- A. Elementos estructurales (cimientos, soportes y vigas).

- $B$. Elementos de albañilería, de compartimentación (paredes de separación y tabiques de distribución), de forrado, o de trasdosado o de la envolvente (fachadas).

- C. Elementos de acabado, revestimiento o terminación (en paredes, suelos y techos).

Algunas fisuras del primer grupo (A) pueden ser sintomáticas de la pérdida de seguridad de la estructura por su falta de resistencia o estabilidad, mientras que algunas fisuras del segundo grupo (B) pueden ser sintomáticas de pérdidas de habitabilidad por pérdida de estanquidad, dificultades de uso, etc. Las fisuras del último grupo (C) tienen un posible impacto principalmente estético, aunque alguna podría afectar mínimamente a las condiciones de uso normal de la zona afectada del edificio. Las fisuras del grupo A se manifiestan en $\mathrm{B}$ y en C, y las del B en el C; a la inversa no es así.

Para la valoración técnica de las fisuras que afectan a cerramientos y acabados (B y C) existen algunos patrones de referencia para casos específicos, como daños por asiento de edificios (9-11), para el caso de sacudidas sobre edificaciones (12), para el caso de terremotos (13) y para fábricas no armadas (14), pero no son directamente aplicables a nuestro caso por no ser este tipo de fisuras indicativas de daños estructurales, por lo que se han establecido los criterios que se indican más adelante. Como referencia técnica genérica hemos mantenido los requisitos básicos establecidos por el art. ${ }^{0} 3$ de la LOE (15) y las exigencias básicas establecidas en el $\mathrm{C}^{\circ} 3$ de la parte I del CTE (16).

\subsection{Clasificación de fisuras por amplitud}

Para los usuarios, los factores más relevantes de una fisura por deformación diferida son el impacto visual y la técnica (coste y molestias) de reparación. Ambos dependen de la amplitud y de la extensión de las fisuras; las más abiertas suelen ser más largas debido a la continuidad del revestimiento y tienen una reparación más costosa. Teniendo en cuenta el impacto visual y la forma de reparación, clasificamos las fisuras en función de la amplitud en:

- $M P$ (muy pequeña): a<0'2mm. Son fisuras irrelevantes, apenas visibles, que no requieren ninguna intervención específica. Se tapan cuando se repinta la pared.

- $\quad P$ (pequeña): a=0’2 0’5mm. Son fisuras capilares, la mayoría apenas apreciables que ocasionalmente pueden llegar a unos o'5mm. Sólo afectan al acabado de yeso del tabique o a la capa de pintura, y la mayoría se tapan con el emplastecido o el simple repintado de los paramentos afectados, aunque en algunas puede ser conveniente colocar una venda preventiva.

- $M$ (media): a=0'5 1mm. Son fisuras que normalmente afectan sólo al revestimiento de yeso y cuya incidencia es meramente estética. Las puede cubrir o reparar un albañil o un pintor con las precauciones habituales, entre las que puede estar el rascado de la fisura con la punta de la paleta, y su relleno, emplastecido y lijado. También pueden requerir la colocación de una venda.

- $G$ (grande): a=1 5mm. Son fisuras que ya parten claramente una cara del ladrillo (y del tabique), al menos. Su reparación requiere la intervención de un albañil para el picado de la pared en el recorrido de la fisura.

- $M G$ (muy grande): a>5mm o con salto de plano $>5 \mathrm{~mm}$. Puede considerarse que afectan al espesor y funcionalidad (v. g. acústica) del tabique (no a su estabilidad), por lo que podrían requerir la demolición y reconstrucción parcial o total del tabique.

\subsection{Afectación de los daños a las prestaciones técni- cas del edificio}

La relevancia técnica de un daño, en una parte del edificio, queda determinada por cómo repercute en las prestaciones técnicas del elemento afectado y del edificio, y a los requisitos básicos establecidos por el art. ${ }^{\circ} 3$ de la LOE, es decir, de su afectación práctica a la ocupación y uso normal del mismo, lo que depende, principalmente, del tipo de daño, de su extensión y de su intensidad.

En nuestro caso, el tipo de daño (fisura) lleva implícita su causa y evolución, y determina las prestaciones técnicas afectadas (v. g. aislamiento acústico), mientras que la extensión del daño (v. g. longitud o número de fisuras) y su intensidad (v. g. amplitud de fisura) determinan el grado de afectación del daño a las prestaciones técnicas del elemento dañado. Los grados de afectación a las prestaciones técnicas del elemento se pueden objetivizar en cinco grupos combinando los diferentes niveles de extensión y de intensidad del daño. En general, consideramos cinco niveles de extensión, de intensidad y de grado de afectación: muy bajo (1), bajo (2), medio (3), alto (4) y muy alto (5), a los que hemos añadido uno previo nulo o prácticamente nulo (o) para los casos en los que los daños fueran de mínima extensión y nula relevancia técnica.

De forma análoga a la técnica de apreciación del riesgo cono-cida como matriz de consecuencia/probabilidad, descrita, por ejemplo, en la norma UNE-EN 31010:2011 (17), utilizamos una matriz de extensión/intensidad, ver tabla 1, para graduar los niveles de afectación de las fisuras a las prestaciones técnicas de los cerramientos, en la que los cinco niveles de extensión y de intensidad se designan con números arábigos (o a 5), y los niveles de afectación a las prestaciones técnicas con números romanos (I a V).

Tabla 1. Matriz de grados de afectación a prestaciones técnicas.

\begin{tabular}{|c|c|c|c|c|c|c|c|}
\hline & & \multicolumn{6}{|c|}{ Niveles de extensión del daño } \\
\hline & & $\mathbf{0}$ & $\mathbf{1}$ & 2 & $\mathbf{3}$ & 4 & 5 \\
\hline \multirow{6}{*}{ 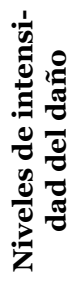 } & $\mathbf{o}$ & - & - & - & I & II & II \\
\hline & 1 & - & I & II & II & III & III \\
\hline & 2 & - & II & II & III & III & IV \\
\hline & $\mathbf{3}$ & I & II & III & III & IV & IV \\
\hline & 4 & II & III & III & IV & IV & $\mathrm{V}$ \\
\hline & 5 & II & III & IV & IV & $\mathrm{V}$ & $\mathrm{V}$ \\
\hline
\end{tabular}




\section{6. Índice de afectación}

La asignación del grado de afectación $\left(G_{A}\right)$ a cada vivienda se hace mediante un índice de afectación $\left(I_{A}\right)$ directamente asociado a los niveles de afectación de las fisuras que haya en la vivienda. Sistemas sobre principios iguales o parecidos han sido previamente propuestos para evaluar, por ejemplo, daños en general (18) o enfoscados de fachadas en particular (19), aunque con procedimientos bastante más complejos.

Así, el índice de afectación " $I_{A}$ " en una vivienda lo obtenemos multiplicando el número de fisuras de cada tamaño (extensión) por el valor relativo correspondiente a su intensidad [1]:

[1] $I_{A}=n_{M P} \times 0+n_{P} \times 1+n_{M} \times 4+n_{G} \times 16+n_{M G} \times 64$

Siendo:

- n: extensión o número de fisuras de cada tamaño (intensidad), según grupos antes descritos, y con estos subíndices:

- $M P$ (fisuras muy pequeñas, $<0$ '2mm), con valor relativo es o (cero).

- $P$ (fisuras pequeñas, o'2 0'5mm), con valor relativo es 1.

- $M$ (fisuras medias, o'5 1'omm), con valor relativo de 4 .

- $G$ (fisuras grandes, $1 \sim 5 \mathrm{~mm}$ ), con valor relativo es de 16 .

- $M G$ (fisuras muy grandes, $>5 \mathrm{~mm}$ ), con valor relativo es de 64.

- El valor relativo asignado a cada tamaño de fisuras (o, 1 , 4, 16 y 64) representa su nivel de intensidad, y sigue una escala geométrica de razón 4 . Se utiliza este tipo de escala para acercarse a la percepción del usuario con la base de la ley psicofísica de Weber-Fechner, según la cual, si un estímulo crece en progresión geométrica, la percepción evolucionará en progresión aritmética y para sobrevalorar a las fisuras más grandes; sin embargo, el uso de escalas con razón 2, o incluso aritméticas, no varía sustancialmente los resultados finales, como hemos comprobado con el cálculo de los diferentes modelos.

\subsection{Grado de afectación}

El grado de afectación de las viviendas se determina finalmente en función del índice de afectación obtenido con la ecuación [1].

A partir del intervalo de valores de los índices $\left(I_{A}\right)$ anteriores, teniendo en cuenta los casos con índices máximos, se divide el dicho intervalo en varios grupos correspondientes a los siguientes valores, según una escala geométrica también de razón 4, resultando así los siguientes grados de afectación $\left(G_{A}\right)$ :

- $-G_{A}$ nulo o prácticamente nulo: $\mathrm{I}_{\mathrm{A}}=0$. Corresponde a viviendas sin fisuras o con fisuras y menores de o'2mm.

- $G_{A}=\mathrm{I}$. Muy bajo: $\mathrm{I}_{\mathrm{A}}=0$ a 4 . Corresponde a viviendas que tienen menos de 4 fisuras de abertura o'2 0'5mm.

- $G_{A}=$ II. Bajo: $\mathrm{I}_{\mathrm{A}}=5$ a 16 . Corresponde a viviendas que tienen entre 4 y 15 fisuras de abertura de o'2 0'5mm o menos de 4 fisuras de abertura de o' $5 \sim 1 \mathrm{~mm}$, o cualquier combinación intermedia equivalente.

- $G_{A}=$ III. Medio: $\mathrm{I}_{\mathrm{A}}=17$ a 64 . Corresponde a viviendas que tienen entre 4 y 15 fisuras de abertura de o'5 1mm o menos de 4 fisuras de abertura de $1 \sim 5 \mathrm{~mm}$, o cualquier combinación intermedia equivalente.

- $G_{A}=$ IV. Alto: $\mathrm{I}_{\mathrm{A}}=65$ a 256 . Corresponde a viviendas que tienen entre 4 y 15 fisuras de abertura de $1 \sim 5 \mathrm{~mm}$ o menos de 4 fisuras de abertura mayor de $5 \mathrm{~mm}$, o cualquier combinación intermedia equivalente.

- $G_{A}=V$. Muy alto: $\mathrm{I}_{\mathrm{A}}>256$. Corresponde a viviendas que tienen más de 4 fisuras de abertura mayor de $5 \mathrm{~mm}$.

Conforme al grado de afectación, la técnica y el tiempo de reparación de las fisuras son diferentes, y así se deberá tener en cuenta para la valoración económica correspondiente.

\section{CASOS DE ESTUDIO}

Para contrastar este procedimiento de inspección y de valoración técnica, hemos inspeccionado un total de 6 conjuntos residenciales con las siguientes características:

- Conjunto 1. Bloque en manzana cerrada con patio interior privado. Está compuesto por 12 portales, de planta baja más 4 plantas y 4 plantas de sótano. El sótano es común con 4 plantas dedicadas a garajes y trasteros. El conjunto tiene un total de 154 viviendas y se inspecciona 8 años después de la puesta en carga de la estructura.

- Estructura. Forjados unidireccionales de canto $30+5 \mathrm{~cm}$, con vigas planas de hormigón con luces entre 4-7m, y viguetas in situ con luces entre $5{ }^{\prime} 5^{-6}{ }^{\prime} 5 \mathrm{~m}$.

- Tabiquería. Ladrillo cerámico de gran formato $(\sim 50 \times 70 \mathrm{~cm})$.

- Conjunto 2. Está formado por 4 bloques exentos con un portal en cada bloque. El sótano es común y de una sola planta, que ocupa la práctica totalidad de la parcela destinado a garaje y trasteros. El conjunto tiene un total de 88 viviendas y se inspecciona 8 años después de la puesta en carga de la estructura.

- Estructura. Forjados bidireccionales de canto $25+5 \mathrm{~cm}$, con intereje $80 \mathrm{~cm}$ y luces entre $3-5$ ' $5 \mathrm{~m}$.

- Tabiquería. Ladrillo cerámico de gran formato $(\sim 50 \times 70 \mathrm{~cm})$.

- Conjunto 3. Bloque en manzana cerrada con patio interior privado. Está compuesto por 8 portales, de planta baja más 5 plantas. El sótano es común con 2 plantas dedicadas a garajes y trasteros. El conjunto tiene un total de 94 viviendas y se inspecciona 7 años después de la puesta en carga de la estructura.

- Estructura. Forjados unidireccionales de canto $30+5 \mathrm{~cm}$, con vigas planas de hormigón con luces 4-6'5m y viguetas pretensadas con luces entre 4-6'2m.

- Tabiquería. Ladrillo cerámico de tabicón $(\sim 30-40 \mathrm{~cm})$.

- Conjunto 4. Está formado por 3 bloques. El sótano es común de una sola planta con un segundo sótano bajo el primer bloque, destinado a garaje y trasteros. El conjunto tiene un total de 187 viviendas y se inspecciona 7 años después de la puesta en carga de la estructura.

- Estructura. Forjados bidireccionales de canto $30+5 \mathrm{~cm}$, con intereje $85 \mathrm{~cm}$ y luces entre $4-6^{\prime} 9 \mathrm{~m}$.

- Tabiquería. Ladrillo cerámico de gran formato $(\sim 50 \times 70 \mathrm{~cm})$.

- Conjunto 5. Está formado por un único bloque con 4 portales con planta baja más 4 plantas. El sótano es común y de dos plantas situadas bajo los cuatro portales destinado a garaje y trasteros. El conjunto tiene un total 143 viviendas y se inspecciona 9 años después de la puesta en carga de la estructura.

- Estructura. Forjados unidireccionales de canto $30+5 \mathrm{~cm}$, con vigas planas de hormigón con luces $4-6^{\prime} 7 \mathrm{~m}$ y viguetas pretensadas con luces entre $4-5^{\prime} 5 \mathrm{~m}$.

- Tabiquería. Ladrillo cerámico de gran formato $(\sim 50 \times 70 \mathrm{~cm})$. 
- Conjunto 6. Bloque en manzana cerrada con patio interior privado. Está compuesto por 6 portales, de planta baja más 5 plantas. El sótano es común con 2 plantas dedicadas a garajes y trasteros. El conjunto tiene un total de 120 viviendas y se inspecciona 13 años después de la puesta en carga de la estructura.

- Estructura. Forjados unidireccionales de canto $25+5 \mathrm{~cm}$, con vigas planas de hormigón con luces $4-5 \mathrm{~m}$ y viguetas pretensadas con luces entre 4-6m.

- Tabiquería. Ladrillo cerámico de tabicón ( 30-40cm).

Tabla 2. Edad de las estructuras desde la puesta en carga hasta la aparición de los daños y su medición.

\begin{tabular}{|c|c|c|c|}
\hline Conjunto & $\begin{array}{c}\text { Duración } \\
\text { obra (me- } \\
\text { ses) }\end{array}$ & $\begin{array}{c}\text { Aparición } \\
\text { daños } \\
\text { (meses) }\end{array}$ & $\begin{array}{c}\text { Medición } \\
\text { daños } \\
\text { (meses) }\end{array}$ \\
\hline 1 & 21 & - & 98 \\
\hline 2 & 23 & 21 & 104 \\
\hline 3 & 17 & 43 & 86 \\
\hline 4 & 25 & 48 & 89 \\
\hline 5 & 17 & 80 & 117 \\
\hline 6 & 17 & - & 162 \\
\hline
\end{tabular}

\subsection{Edad de las estructuras}

La flecha diferida depende tanto del tiempo que lleva la carga aplicada como de la edad a la que se realiza la medición. La puesta en carga de la estructura la estimamos a partir de la fecha del Acta de Replanteo y del Certificado Final de Obra, suponiendo que sucede a mitad de la obra salvo que tengamos otros datos más precisos. Para estimar cuando aparecieron los daños utilizamos la primera mención que realizan los propietarios de las viviendas referente a la aparición de fisuras en tabiquerías o techos. Finalmente, en la tabla 2 también indicamos el tiempo transcurrido cuando hicimos nuestra inspección de los daños.

\section{RESULTADOS Y DISCUSION}

Durante nuestra inspección, visitamos todas las viviendas en las que los propietarios indicaron que tenían daños, que resultaron ser 291 viviendas en los 6 conjuntos.

\subsection{Tipos de daños}

Los daños más comunes son fisuras debidas a los esfuerzos mecánicos generados por las deformaciones que la estructura induce en las tabiquerías. También aparecen pliegues de pintura y, rara vez, aplastamientos. En general las fisuras tienden a repetirse con la misma posición y trazado en la vertical de las viviendas, aunque varía su intensidad. Clasificamos los daños en dos grupos:

\section{- A. Daños en tabiquerías y trasdosados:}

- Fisuras horizontales y verticales en los trasdosados bajo las ventanas (figura 8-a). Tipo $h$ y $v$ de figura 1.

- Fisuras verticales en las mochetas que configuran los forrados de ladrillo de los pilares de fachada (figura 8-b). Tipo $e$ de figura 1.
- Aplastamiento de retacados de yeso superiores de tabiques, generalmente iniciadas en la pared de fachada, pero prolongándose más o menos por las paredes perpendiculares (figura 8-c). Tipo $r$ y $z$ de figura 1.

- Fisuras verticales en los tabiques que parten del suelo hacia arriba. Suelen aparecer en tabiques perpendiculares a las fachadas en el medio de la luz (figura 9-a). Tipo $v$ de figura 1.

- Fisuras inclinadas junto a registros de instalaciones y puertas de paso que se inician en las esquinas (figura 9-b). Tipo $i$ de figura 1.

- Desprendimiento de guarnecidos de yeso en zonas inferiores por aplastamiento de tabiquerías en plantas bajas (figura 9-c). Tipo $d$ de figura 1.

- Roturas o aberturas de juntas de chapados y alicatados de cuartos húmedos (figura 10-a).

- B. Daños en techos:

- Fisuras en tabicas y falsos techos de escayola (fig. 10-b). Tipo $t$ de figura 1 .

- Pliegues de pintura en guarnecidos de techo por aplastamiento (figura 10-c).

\subsection{Amplitud de fisuras}

Las fisuras aparecen en todas las viviendas examinadas y en casi todas las viviendas afectadas hay fisuras de diferentes tamaños, pero sin embargo la mayor parte de los daños tienen poca relevancia técnica, aunque generan la comprensible preocupación y queja de los propietarios. En la figura 11 se representan los porcentajes de fisuras en función de la amplitud que hemos medido en los diferentes conjuntos residenciales.

\subsection{Grados de afectación}

Una vez inspeccionadas todas las fisuras se clasificaron por tamaños, se calcularon los índices de afectación de las viviendas y finalmente se clasificaron las viviendas según sus grados de afectación. En las tablas 3 a 8 se esquematizan las viviendas de los diferentes conjuntos con indicación de su grado de afectación. En la figura 12 se representan los porcentajes de viviendas según su grado de afectación.

De las 291 viviendas examinadas, ninguna tenía un grado de afectación $\left(G_{A}\right)$ muy alto, 27 (9'3\%) tenían un grado de afectación alto, 92 (31'6\%) medio, 98 (33'7\%) bajo, 61 (21'o\%) muy bajo y 13 (4'5\%) nulo o irrelevante. Por lo tanto, el 90'7\% tiene un grado de afectación igual o inferir a medio $\left(G_{A}=\mathrm{III}\right)$.

De las 27 viviendas con un grado de afectación alto, 15 (55'5\%) se encuentran situadas en la planta más baja de viviendas, con la planta inferior diáfana, ya sea destinada a soportales, locales o garajes. Esto se debe a que el peso de los tabiques y las cargas de cada planta son soportados por su forjado de suelo, que con su deformación transmite parte de su carga a los tabiques de la planta inferior. Esto sucede progresivamente hasta llegar a una planta que no tenga tabiques bajo ella, que suele ser la baja sobre garaje o la primera sobre soportales. Así, los tabiques de la planta más baja tienen que soportar la parte acumulada de las cargas de los tabiques de las plantas superiores, y por lo tanto existe una mayor probabilidad de que aparezcan fisuras en ellos.

En la construcción tradicional esta circunstancia no sucedía, y las tabiquerías en muchos casos llegaban hasta el terreno y se apoyaban en pequeñas zapatas; además, en muchos casos, 

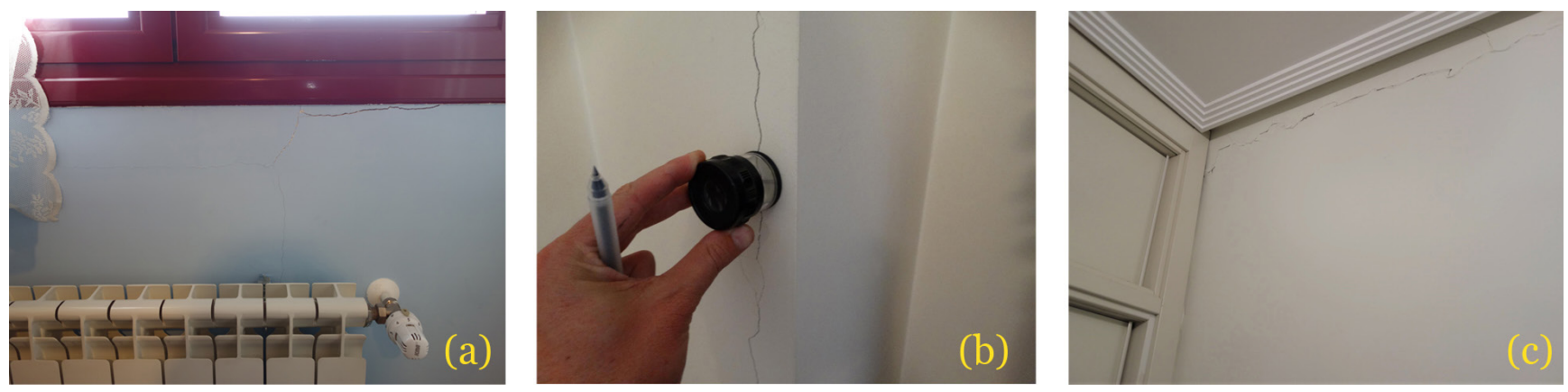

Figura 8. Daños en tabiquerías y trasdosados: (a) Fisuras bajo ventanas, (b) medición con lupa micrométrica de fisuras verticales en mochetas, (c) aplastamiento de retacados de yeso.
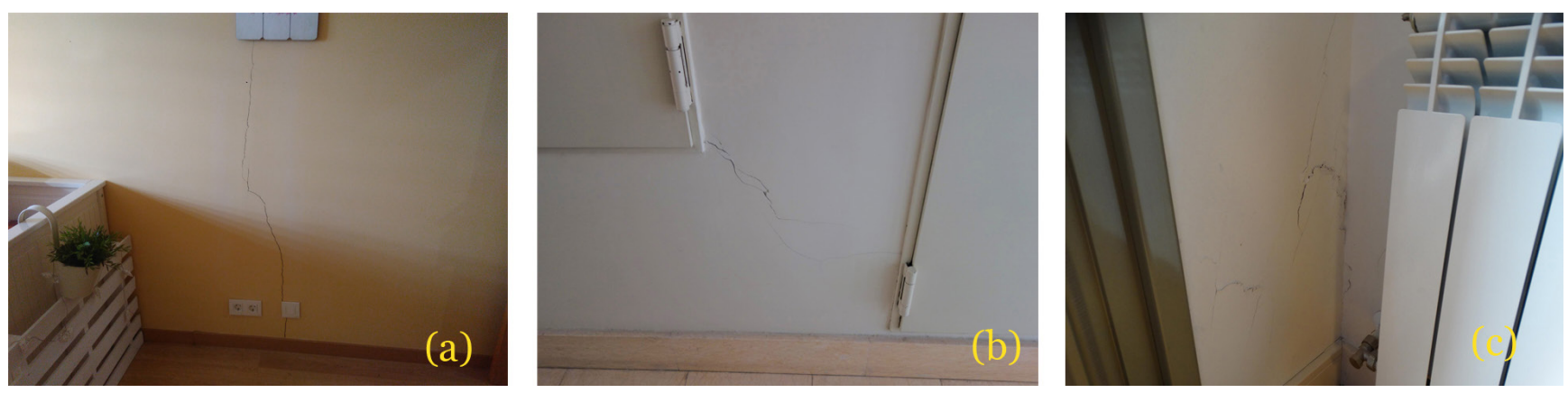

Figura 9. Daños en tabiquerías y trasdosados: (a) Fisuras verticales en tabiques perpendiculares a fachada, (b) fisuras inclinadas en registros de instalaciones, (c) desprendimientos de guarnecidos por aplastamiento en plantas bajas.
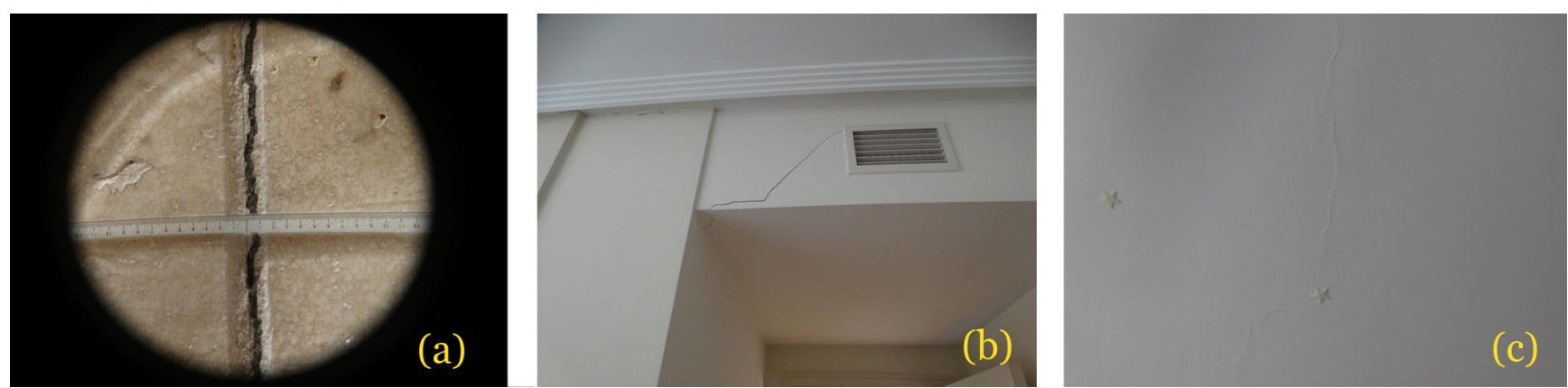

Figura 10. Daños en aplacados: (a) Apertura de juntas. Daños en techos: (b) Fisuras en tabicas y falsos techos de escayola, (c) pliegues en pinturas.

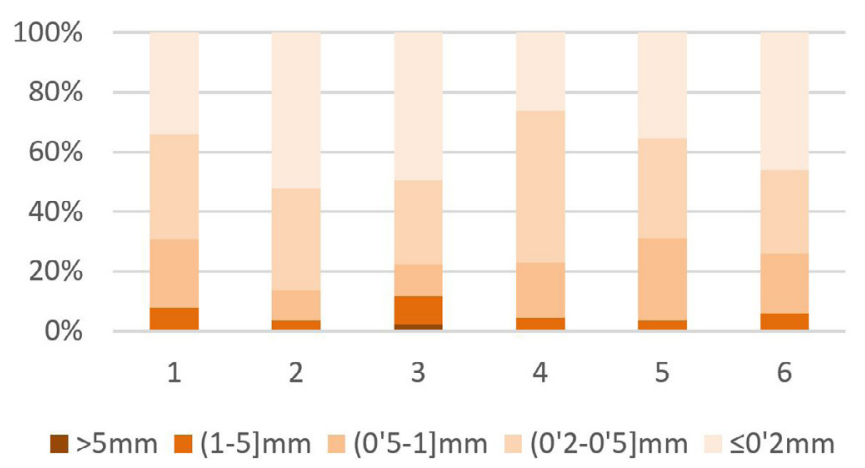

Figura 11. Porcentajes de fisuras distribuidas por amplitud.

se seguía la práctica de hacer la estructura de abajo hacia arriba y la albañilería de arriba hacia abajo.

Los daños que tienen una elevada extensión afectan a una media del $40 \%$ de las viviendas de cada conjunto. Los resultados muestran los riesgos de ejecutar forjados no pretensados

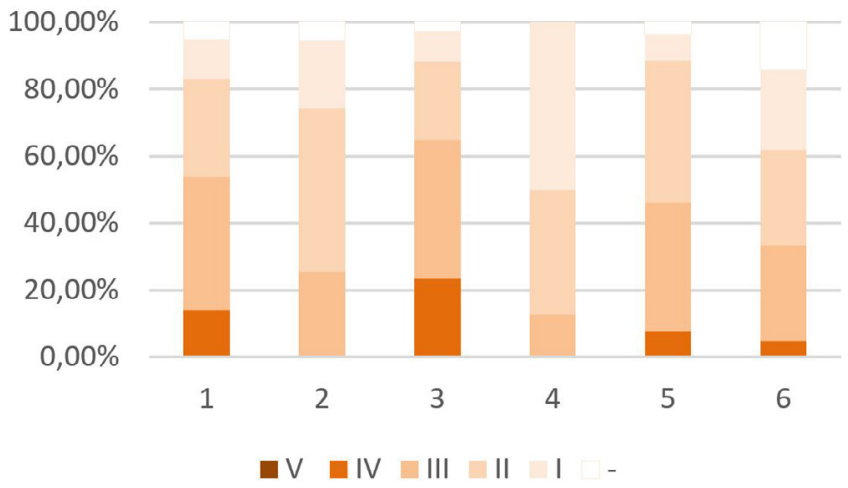

Figura 12. Porcentajes de viviendas por grados de afectación.

con esbelteces geométricas, $\lambda$, por encima de 16 . Las estructuras de los conjuntos 1 y 5 tienen esbelteces similares tanto de vigas, $\lambda_{v}=19 \sim 20$, como de forjados, $\lambda_{f}=16$, diferenciándose en que el conjunto 1 tiene las viguetas in situ, frente a las pretensadas del conjunto 5. Analizando los resultandos observamos que el conjunto 1 tiene el mayor porcentaje de vivienda afec- 
tadas, 73'4\% (tabla 3), frente al conjunto 5 que tiene el menor porcentaje de viviendas afectadas, 18 '2\% (tabla 7).

El pretensado de viguetas muestra su eficacia para reducir la aparición de daños, pues consiste en una precompresión del hormigón que evita la aparición de tracciones y fisuras en el hormigón. Las fisuras reducen la inercia de la sección fisurada y conlleva a unas mayores deformaciones y a la aparición de un mayor número de daños.

Las estructuras bidireccionales, conjuntos 2 y 4, tienen un número de viviendas afectadas similar al resto. Sin embargo, se observa que no aparecen viviendas con grados de afectación alto o muy alto, el mayor grado de afectación es medio.

En cuanto a la influencia del tipo de tabiquería, observamos que la mayoría de las viviendas afectadas (87'4\%), tienen tabiquería de gran formato. Esto nos indica que el aumento de tamaño de las piezas cerámicas reduce el número de juntas y conlleva a una debilitación de los tabiques, que se refleja en la mayor aparición de fisuras en los mismos.

\subsection{Evolución de los daños}

La flecha diferida del hormigón depende de la tensión y del tiempo y se origina por la fluencia del hormigón. Ésta depende de múltiples factores, como la humedad relativa, la edad de la carga, el tipo de cemento, la resistencia del hormigón o el proceso de descimbrado. En la norma española (3) la flecha diferida se estima a partir de la flecha instantánea multiplicándola por un coeficiente, sin tener en cuenta hechos como descimbrados tempranos o escasos apuntalamientos, lo que hace que esta fórmula no esté suficientemente calibrada. En los casos de estudio, tabla 2, observamos que las primeras fisuras aparecen al año de puesta en carga de las estructuras (conjunto 2); la media y la moda coinciden a los tres años (conjuntos 3 y 4) y en el caso más tardío aparecieron a los seis años (conjunto 5).

Todas nuestras inspecciones se realizaron tras más de 7 años de puesta en carga de las estructuras, y realizamos un ensayo de comprobación de estabilización en el conjunto 6 , una vez que habían pasado 13 años desde la puesta en carga y con mediciones a lo largo de un año. Colocamos 4 testigos dispuestos en rectángulo, uno en una fisura vertical y el resto en fisuras inclinadas, en diferentes plantas.

La desviación típica obtenida de las diferencias de medidas de los lados que no cruzan fisuras, con el pie de rey digital, fue de $\sigma=0$ '07mm. Asumiendo una distribución normal de los errores de lectura, las variaciones dimensionales medidas serian estadísticamente significativas a partir de diferencias de $3 \times \sigma=0$ '21mm.

Con los datos obtenidos se concluye que las fisuras monitorizadas, y las deformaciones que las originaron, estaban estabilizadas en todos los casos de estudio descritos.

\subsection{Reparación de los daños}

Una vez que se ha comprobado que la deformación del edificio se ha estabilizado, mediante de la medición de la variación de la amplitud de las fisuras en el tiempo, solo queda reparar los daños. Este es el punto más importante en la práctica, puesto que conlleva la valoración económica de la reparación, y por lo tanto de la posible indemnización.
Como ya dijimos, las fisuras que son menores de o'2mm no requieren ninguna reparación específica;-se podrán tapar cuando se repinten los recintos en los que aparecen en las operaciones de mantenimiento de la vivienda cuando han pasado más de 5 años. Para las de más amplitud no se requiere más que el cierre de las fisuras, con el ocasional repaso de sus bordes y el repintado de los paramentos afectados, que según el grado de afectación implica, básicamente, las operaciones que detallamos a continuación:

- Viviendas con $G_{A}=\mathrm{I}$, muy bajo: repintado de paramentos, con el enmasillado ocasional de alguna fisura. Se estima más que suficiente una jornada de trabajo de dos pintores, oficial y ayudante y $20 \mathrm{~m}^{2}$ de superficie a pintar.

- Viviendas con $G_{A}=$ II, bajo: repintado de paramentos, con el enmasillado de fisuras. Se estima más que suficiente una jornada y media de trabajo de un oficial pintor y una jornada de ayudante, y $30 \mathrm{~m}^{2}$ de superficie a pintar.

- Viviendas con $G_{A}=\mathrm{III}$, medio: repintado de paramentos, con raspado de labios de fisuras, enmasillado y colocación de venda de fibra de vidrio. Se estima más que suficiente dos jornadas de trabajo de dos pintores, oficial y ayudante, y $40 \mathrm{~m}^{2}$ de superficie a pintar.

- Viviendas con $G_{A}=\mathrm{IV}$, alto: repintado de paramentos, con raspado de labios de fisuras, enmasillado y colocación de venda de fibra de vidrio. Se estima más que suficiente tres jornadas de trabajo de oficial pintor y dos jornadas de ayudante, y $60 \mathrm{~m}^{2}$ de superficie a pintar.

- Viviendas con $G_{A}=\mathrm{V}$, muy alto: reparación de elementos de tabiquería dañados mediante picado de guarnecidos alrededor de la grieta, retirada y recolocación de ladrillos y ejecución de nuevo guarnecido. Repintado de paramentos, con raspado de labios de fisuras, enmasillado y colocación de venda de fibra de vidrio. Se estima más que suficiente una jornada de trabajo de un oficial de albañilería y ayudante, tres jornadas de trabajo de oficial pintor y dos jornadas de ayudante, y $80 \mathrm{~m}^{2}$ de superficie a pintar.

\section{CONCLUSIONES}

La flecha diferida de las estructuras de hormigón es un fenómeno esperable, la causa que lo origina es ampliamente conocida. La peritación de los daños que ocasiona, típicamente fisuras en tabiques y techos, se centra en evaluar el alcance de éstos con el objetivo de que la valoración económica de la reparación de los daños sea lo más acertada posible.

Los daños ocasionados por la flecha tienen una amplia extensión y afectan a un elevado número de viviendas. Sin embargo, la mayoría de las fisuras tienen aberturas por debajo de $1 \mathrm{~mm}$, afectan únicamente al acabado y son de fácil reparación. Se observa que el pretensado de las viguetas reduce el número de viviendas afectadas, y que los conjuntos con forjados bidireccionales tienen viviendas con grados de afectación menores que las unidireccionales.

La aparición y evolución de los daños depende de múltiples factores, es necesario confirmar que la fluencia del hormigón ha llegado a un estado en el que deja de producir daños antes de proceder a la reparación. La medición mediante clavos para control con calibre permite conocer de una manera fácil, económica y precisa la evolución de los daños. En función del tipo de fisura proponemos diferentes disposiciones geométricas, triángulos y rectángulos, que permiten conocer directamente-la abertura de la fisura, el desplazamiento (horizontal) 
Tabla 3. Distribución de grados de afectación en las viviendas del conjunto 1.

\begin{tabular}{|c|c|c|c|c|c|c|c|c|c|c|c|c|c|c|c|c|c|c|c|c|c|c|c|c|c|c|c|c|c|c|c|c|c|c|}
\hline & \multicolumn{4}{|c|}{ P.1 } & \multicolumn{3}{|c|}{ P.2 } & \multicolumn{4}{|c|}{ P.3 } & \multicolumn{2}{|c|}{ P.4 } & \multicolumn{2}{|c|}{ P.5 } & \multicolumn{2}{|c|}{ P.6 } & \multicolumn{4}{|c|}{ P. 7} & \multicolumn{2}{|c|}{ P.8 } & \multicolumn{4}{|c|}{ P.9 } & \multicolumn{2}{|c|}{ P.10 } & \multicolumn{3}{|c|}{ P.11 } & \multicolumn{2}{|c|}{ P.12 } \\
\hline & $\mathbf{A}$ & B & $\mathbf{C}$ & D & $\mathbf{A}$ & B & C & $\mathbf{A}$ & B & C & D & $\mathbf{A}$ & B & $\mathbf{A}$ & B & $\mathbf{A}$ & B & $\mathbf{A}$ & B & C & D & $\mathbf{A}$ & B & $\mathbf{A}$ & B & C & D & $\mathbf{A}$ & B & $\mathbf{A}$ & B & C & $\mathbf{A}$ & B \\
\hline $4^{\circ}$ & III & & IV & III & III & & III & - & II & II & III & & II & II & II & - & I & IV & III & & & III & II & & & III I & III & III & & II & II & I & & II \\
\hline $3^{\mathbf{o}}$ & - & & III & II & II & - & & & III & III & III & & & II & & I & I & II & III & III & IV & II & & III & III & & III & II & IV & & I & II & $\mathrm{I}$ & I \\
\hline $\mathbf{2}^{\mathbf{0}}$ & III & III & II & IV & II & & I & III & & & & II & & I & I & II & II & III & III & III & IV & I & & & III I & III I & II & III I & IV & III & II & $\begin{array}{lll}\text { II } & \text { I }\end{array}$ & IV & II \\
\hline $\mathbf{1}^{\mathbf{o}}$ & II & III & III & & & I & & IV & & III & III & III & III & II & III & & II & - & & IV & & & & & & & IV & II & II & II & III I & III & & IV \\
\hline $\mathbf{B}^{\mathbf{0}}$ & III & III & - & III & II & & & IV & II & II & & III & & III & & & & & & & & & & & & & & & IV & & I & & IV & \\
\hline & & & & & & & & & & & & & & & & & & & & & & & & & & & & & & & & & & \\
\hline
\end{tabular}

Tabla 4. Distribución de grados de afectación en las viviendas del conjunto 2 .

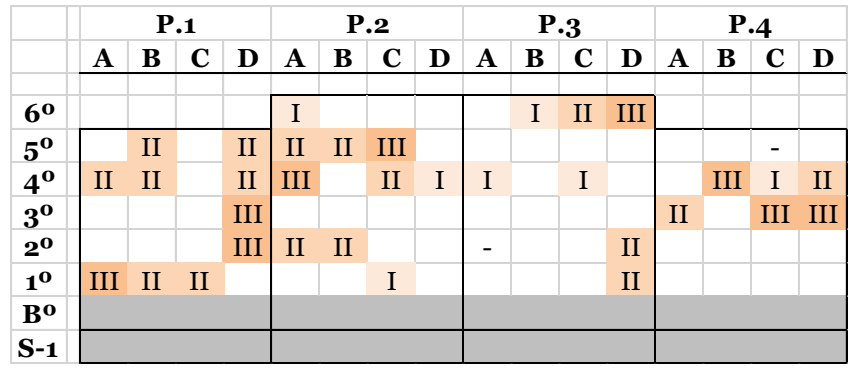

Tabla 5. Distribución de grados de afectación en las viviendas del conjunto 3 .

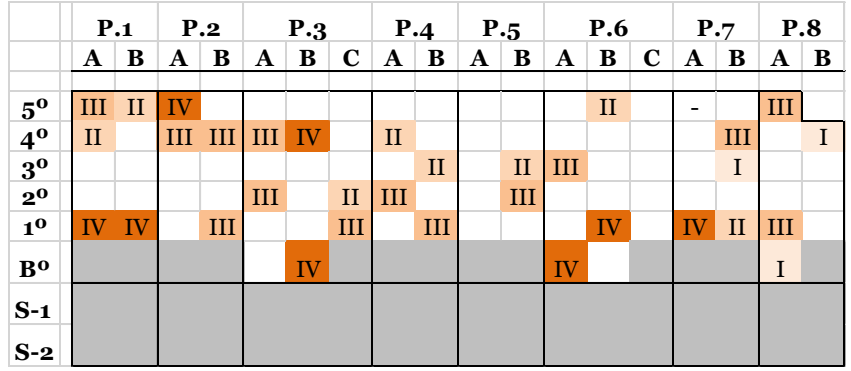

Tabla 6. Distribución de grados de afectación en las viviendas del conjunto 4 .

\begin{tabular}{|c|c|c|c|c|c|c|c|c|c|c|c|c|c|c|c|c|c|c|c|c|c|c|c|c|c|c|c|c|c|c|c|c|c|c|c|}
\hline & & & & .1 & & & & & & & P.2 & & & & P.3 & & P. & & & & P.5 & & & P.6 & & & P.7 & & & & P.8 & & & P.9 & \\
\hline & A & B & C & D & $\mathbf{E}$ & $\mathbf{F}$ & $\mathbf{G}$ & A & B & $\mathbf{C}$ & D $\quad \mathbf{E}$ & $\mathbf{F}$ & $\mathbf{G}$ & A $\mathbf{B}$ & B C & $\mathbf{A}$ & B & C I & D & A & B & $\begin{array}{ll}C & \text { D } \\
\end{array}$ & A & $\begin{array}{ll}A \quad B \\
\end{array}$ & C & $\underline{\mathbf{A}}$ & B & C D & D $A$ & A B & $\begin{array}{ll} & \text { C } \\
\end{array}$ & D & & & $\begin{array}{lll}\mathbf{C} & \mathbf{D} \\
\end{array}$ \\
\hline $5^{\circ}$ & I & III & & & & & & & II $\quad$ II & $\begin{array}{ll}\mathrm{II} & \mathrm{I}\end{array}$ & $\begin{array}{ll}\text { II } & \text { II }\end{array}$ & & & & & & & & & & & & & & & & & & & & & & & & \\
\hline $4^{\circ}$ & & II & II & II & II & II & & & & & & I & & & & II I & I & & & & II & & & III & I & I & II & & & & I & I & II I I & I & \\
\hline $3^{\mathbf{o}}$ & & I & II & II & II & II & I & & & & III & I & & & & & & I & I & I $\quad$ I & II I & & & II & & & III II & III & & $\begin{array}{ll}I & \text { I }\end{array}$ & & & & I & \\
\hline $2^{\mathbf{o}}$ & & & & & & & & I & & & & II & & I & I & & & & & & I & I & I & & & & & & & II & & & & & I \\
\hline $\mathbf{1}^{\mathbf{o}}$ & & & III & & & & & & III I & & & & I & & & III I & & & & & II I & & & & I & & & & & II I & & & & & \\
\hline $\mathbf{B}^{\mathbf{0}}$ & & & & & & & & & & & & & & & & & & & & I & I & & & & & & & I & & & & & & & \\
\hline S-1 & & & & & & & & & & & & & & & & & & & & & & & & & & & & & & & & & & & \\
\hline $8-2$ & & & & & & & & & & & & & & & & & & & & & & & & & & & & & & & & & & & \\
\hline
\end{tabular}

Tabla 7. Distribución de grados de afectación en las viviendas del conjunto 5 .

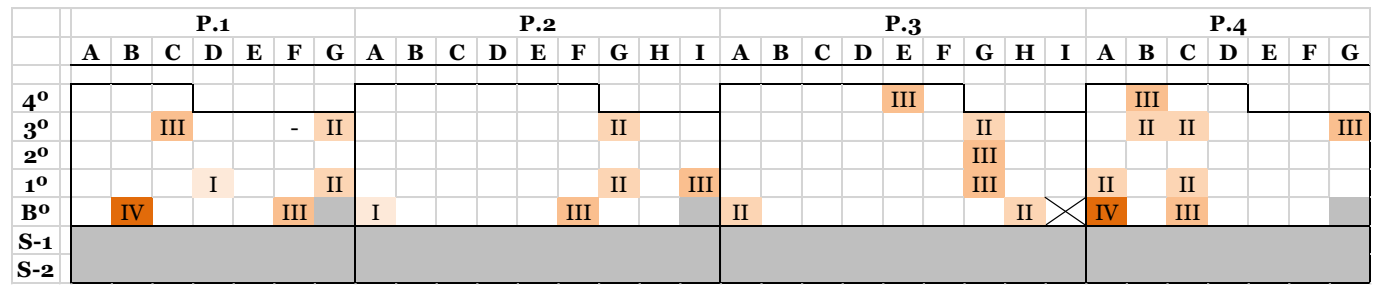

Tabla 8. Distribución de grados de afectación en las viviendas del conjunto 6.

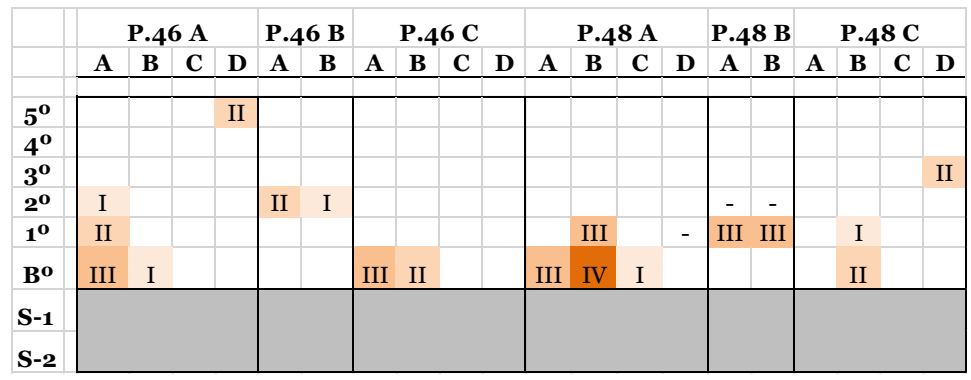


y el asiento (vertical) de las partes del tabique, así la exactitud y la precisión estadística de la medición.

En el artículo hemos mostrado herramientas y procedimientos que permiten caracterizar y medir las fisuras, junto con unas fichas sencillas que sistematizan la toma de datos du- rante las inspecciones. Con los datos obtenidos, utilizamos un método que permite calcular un índice de afectación de cada vivienda para clasificarlas objetivamente en función de su grado de afectación. Las operaciones de reparación de los daños y su consiguiente valoración económica se establecen en función de este grado de afectación en cada vivienda.

\section{REFERENCIAS / REFERENCES}

(1) Carretero, M.J., Moreno A. (2016). Análisis estadístico sobre patologías en edificación II. Madrid: Fundación Musaat.

(2) Calavera, J., Garcia, L., Rodriguez, R. (2009). Cálculo de flechas en estructuras de hormigón armado. Intemac.

(3) EHE (2008). Instrucción del Hormigón Estructural 2008: España: Ministerio de la Presidencia.

(4) Serrano, D. (2018). Guía tecnológica del arquitecto perito. UAPFE.

(5) Ortega Andrade, F. (1987). Código para la representación de fisuras producidas en paredes, sobre los planos de plantas. Revista de edificación, $\mathrm{N}^{\mathrm{O}} 1,23-26$.

(6) Lao, E.; Martín-Vargas, D.; Ruiz-Sánchez, A. (2017). El protocolo de grietas en el estudio patológico del edificio. COAATIEMCA. http://www.coaatmca.com/wp-content/uploads/2017/10/encarte-mares-14.pdf.

(7) Serrano Alcudia, F. (2005). Patología de la edificación. El lenguaje de las grietas. Fundación Escuela de la Edificación, C.O.A. y A.T. Madrid. $3^{\mathrm{a}}$ ed. ampl. y corr.

(8) Cigni, G. (1978). Il consolidamento murario. Tecniche d'intervento. Ed. Kappa, Roma.

(9) Burland, J.B., Wroth, C.P. (1974). Settlement of buildings and associate damage, SOA Review. Conf Settlement of structures, Cambridge, Pentech Press, Londres, (pp 611-654).

(10) Driscoll, R. (1995). Assessment of damage in low-rise buildings, with particular reference to progressive foundation movement, Building Research Establishment (BRE) Digest 251. Watford, United. Kingdom.

(11) AS 2870 (1996). Residencial slabs and footings. Standards Australia.

(12) SN 640.312:1992. Schweizerische Normen-Vereinigung, Les ébranlements - Effet des ebranlements sur les constructions. Swiss Association for Standardization.

(13) FHECOR Ingenieros Consultores (2013). Guía de inspección y evaluación de emergencia de edificios.

(14) Mehdizadeh Saraj, F. (2008). A comprehensive approach towards the classification of cracks in un-reinforced masonry buildings. IUST International Journal of Engineering Science, Architect Engineering, Special Issue Vol. 19, No.6, 41-52.

(15) LOE (Ley 38/1999). Ley de Ordenación de la Edificación. España: Jefatura del Estado.

(16) CTE (RD 314/2006). Código Técnico de la Edificación. España: Ministerio de Fomento.

(17) UNE-EN 31010:2011. Gestión del riesgo. Técnicas de apreciación del riesgo. AENOR

(18) Ruiz Gorrindo, F. (2014). Escala de gravedad de daños en edificios: de la asignación directa a la contrastación estadística. Tesis doctoral. Universidad Politécnica de Catalunya. http://hdl.handle.net/10803/285004.

(19) Lima, P.; De Brito, J. (2013). Damage in rendered façades. En Peixoto, V. (Ed), A state of the art report on building pathology (pp.115-122). Oporto: CIB. 